\title{
UGOTAVLJANJE IN POTRJEVANJE ZNANJA
}

Nataša

E. Jelenc

Andragoški center

Slovenije

\section{Projekt za formalno potrditev neformalno pridobljenega znanja}

$\mathrm{N}$

ajprej bomo predstavili utemeljitev projekta Ugotavljanje in potrjevanje znanja $(\mathrm{v}$ nadaljevanju UPZ), ciljne skupine, definicijo in bistvo UPZ. Opredelili bomo vrsto znanja, primernega za ocenjevanje v UPZ. Na kratko bomo spregovorili o izhodiščil in nastanku same dejavnosti, nekoliko dlje se bomo zadržali pri opredelitvi in določanju standardov znanja, enega izmed bistvenih elementov UPZ, podrobneje bomo spregovorili o vlogi svetovalca na eni in ocenjevalca na drugi strani, opisali proces UPZ in na koncu predstavili še nekaj sodobnih metod ocenjevanja znanja, primernih za UPZ.

\section{ZAKAJ SMO SE LOTILI PROIEKTA?}

Projekt UPZ je zastavljen skladno $\mathrm{z}$ razvijanjem teoretične podlage in aplikativne rešitve, na podlagi katerih bo mogoče v Sloveniji razvijati centre (središča, možnosti) za ugotavljanje in potrjevanje znanja, različno pridobljenega zunaj formalnih oblik izobraževanja. Razlogi za to so različni: marsikdo ima veliko znanja, ki si ga je pridobil zunaj šolskega izobraževanja, z opravljanjem različnega dela (delovne izkušnje) ali kako drugače (samostojno, skupaj z drugimi ljudmi, prek raznih priročnikov, televizije in drugih medijev, študijskega gradiva ipd.). Posamezniki so si lahko pridobili ali celo presegli raven znanja, ki bi ga sicer dosegli v izobraževalnih ustanovah.

Tako pridobljeno znanje ima sicer za posameznika vrednost, če pa ga želi formalno dokazati in potrditi, težko pridobi priložnost za to, ker je ta največkrat povezana s formalnimi pogoji (dokazila o izobrazbi). To omogoča sistem ugotavljanja in potrjevanja znanja, $\mathrm{v}$ katerem je mogoče znanje potrditi. Oblikovanje takega sistema hkrati omogoča ugotavljanje znanja tistim posameznikom, ki se želijo vključiti v kakšno izobraževanje. Ni jim treba obiskovati celotnega izobraževalnega programa, če so si del znanja že pridobili kako drugače, to znanje pa so pripravljeni dokazati $\mathrm{v}$ okviru UPZ.

Sistem UPZ omogoča preverjanje znanja tudi, kadar posameznik nima potrebe po formalnem priznanju in se za to odloči le zaradi lastne samopotrditve.

\section{POTEK UGOTAVLIANIA IN POTRJEVANJA ZNANIA}

\section{Opredelitev znanja, ki se ocenjuje v sklopu UPZ}

$\mathrm{V}$ nasprotju $\mathrm{z}$ oblikovanim sistemom ocenjevanja formalno pridobljenega znanja $\mathrm{v}$ izobraževalnih ustanovah ugotavljamo $\mathrm{v}$ UPZ skoraj praviloma le neformalno pridobljeno

Neformalno pridobljeno znanje je naložba, ki je v družbi, kakršna je današnja, ko so njene »oporne točke" predvsem uradna potrdila, premalo izrabljena. V zadnjem desetletju se je zato povečala teżnja po odkrivanju »skritega « znanja in spretnosti. Smisel iskanja je većnamenski. V ZDA so raziskave pokazale, da je neformalno pridobljeno znanje največkrat enakovredno tistemu, ki je bilo pridobljeno v izobraževalnih ustanovah, nemalokrat pa ima celo večjo praktično vrednost, ker je usmerjeno $\mathrm{v}$ določene naloge. Evidentiranje tako pridobljenega znanja omogoča ustreznejše razporejanje zaposlenih za njihovo opravlianje, posameznikom omogoča napredovanje, pridobitev kvalifikacii, hkrati pa se lahko izognemo izgubi časa in denarja s poučevanjem o stvareh, ki jih že znajo.

znanje. $\mathrm{Z}$ drugimi besedami, to je znanje, ki ostaja neevidentirano, ker ni bilo pridobljeno "pod nadzorom " institucije. Oglejmo si najprej nekaj virov takšnega znanja: 
- znanje, pridobljeno na podlagi življenjskih izkušenj,

- znanje, pridobljeno iz izkušenj na delovnem mestu,

- znanje, pridobljeno s samostojnim učenjem,

- znanje, pridobljeno s pomočjo drugih oseb, pri neformalnem druženju ali neformalnih stikih,

- znanje, pridobljeno pri ukvarjanju z ljubiteljskimi dejavnostmi.

\section{Definicija UPZ}

Ugotavljanje in potrjevanje znanja je dolgotrajnejši proces, pri katerem uradni predstavnik izobraževalnih institucij ali posebej za to določenih teles s kandidatom ugotavlja, kakšno znanje ali kakšne spretnosti ta obvlada. Ni pomembno, kako in kdaj si jih je kandidat pridobil. $V$ procesu UPZ se takšno znanje evidentira, prepozna kot veljavno glede na vnaprej določene standarde znanja (po novem učne dosežke), in izda potrdilo (spričevalo) o tem znanju. Potrdilo izkazuje določeno raven znanja ali spretnosti za določeno področje.

Potrdila/spričevala, ki jih prejmejo kandidati v okviru UPZ, so zelo različna, od potrdil za

Izkustveno

pridobljeno znanje

naj bi bilo

enakovredno

formalno pridoblieni izobrazbi.

\section{Opredelitev vloge in osnovni elementi poteka procesa UPZ}

UPZ ima poleg prepoznavanja znanja/spretnosti še druge vloge, na primer motivirati odrasle, da bi bolje izrabili možnosti za izobraževanje, povečati fleksibilnost organizacij, ustvariti in gojiti pozitiven odnos do vseživljenjskega izobraževanja/učenja.

Dejavnost UPZ se ni začela razvijati naključno. Že prej je bilo slutiti spremembe v pojmovanju izobraževanja in nujnosti nenehnega dopolnjevanja, posodabljanja in spreminjanja znanja/spretnosti. Izobraževalni programi ne morejo zajeti večine prebivalstva, tudi vsi ljudje se ne morejo vključiti vanje. Mnogi si znanje/spretnosti lažje pridobijo bolj ali manj samostojno.

UPZ prinaša koristi posameznikom in delovnim organizacijam, pa tudi širši družbi. Posameznikom omogoča, da ugotovijo in formalizirajo svoje znanje, pridobljeno iz izkušenj ali kako drugače, in da se jim ni treba znova učiti tega, kar že znajo. Skrajša jim čas za pridobitev formalne izobrazbe, jih spodbudi, da se zavedo svojih potreb glede strokovnega razvoja in potreb po izobraževanju. Ker posamezniku priznajo njegovo znanje in sposobnosti, spodbuja UPZ, kot kažejo izkušnje v ZDA in Veliki Britaniji, motiviranost za nadaljnje učenje in s tem se krepi njegova samozavest. Spodbuja ga pri želji za pridobitev kvalifikacije. Izkušnje tudi kažejo, da si kandidati, ki so šli skozi UPZ, upajo v nadaljnjem življenju prevzeti večje odgovornosti. Napredujejo v svoji delovni organizaciji. Pogumneje se podajo naprej v smeri, za katero so se odločili. Učinkoviteje izrabljajo svoje znanje/spretnosti, izbirajo zanimivejša delovna mesta in so osebno bolj zadovoljni. Tudi tistim, ki so izgubili delovno mesto, se običajno po končanem UPZ uspe znova zaposliti. Nekateri pa se celo odločijo korenito spremeniti svojo poklicno pot, odločijo se za študij popolnoma druge smeri (raziskave v okviru Sveta za izobraževanje odraslih in izkustveno učenje - CAEL, The Council for Adult and Experiential Learning, ZDA).

UPZ koristi tudi delovnim organizacijam, ker tako te učinkoviteje izrabijo posameznikove delovne zmožnosti, njegovo znanje in sposobnosti. Motivirajo zaposlene, da se z veseljem lotijo dela, se vpišejo v izobraževalne progra- 
me in jih tudi končajo. Zaposleni imajo enake možnosti. Delovne organizacije lahko UPZ vključijo tudi v svoje službe in izobraževalne programe. Z UPZ si delovna organizacija lahko pomaga ugotavljati sposobnosti in slabosti posameznikov in jim glede na ugotovitve dodeli drugačno delo, pri katerem so učinkovitejši.

UPZ poteka v več fazah (kasneje si bomo vsako posamezno fazo podrobneje ogledali):

- priprava standardov znanj/spretnosti (učnih dosežkov);

- priprava različnih ocenjevalnih metod za predstavitev in dokazovanje znanja/spretnosti;

- ugotavljanje znanja/spretnosti - svetovanje; svetovalec s kandidatom ugotovi, kakšno/kakšne znanje/spretnosti ima in skupaj poiščeta načine, kako bo to/te znanje/spretnosti dokazal, kakšno dokazno gradivo/izdelke mora priskrbeti, kdaj, ali je treba, kako se mora še dodatno pripraviti, da bi izkazal svoje znanje;

- ocenjevanje, sam postopek preverjanja kandidatovega znanja oziroma njegovih spretnosti, izbira primernih metod ocenjevanja in uradna potrditev;

- pregled ocenjevalčevega dela in potrditev na višji ravni.

\section{IZVOR UPZ}

Priznavanje izkustvenega učenja je staro skoraj toliko kot človeštvo, čeprav ni bilo sistematično urejeno in formalizirano. Številni filozofi in misleci so poudarjali pomembnost takšnega učenja za človekov razvoj. V srednjem veku je bil na nekaterih področjih to edini način prenašanja znanja, na primer širjenje znanja $z$ izkušnjami od mojstra do vajenca in formalno priznavanje. Kasneje je potekalo izobraževanje na podlagi vodenih pogovorov med prijatelji in znanci, na primer $\mathrm{v}$ salonih v Franciji in Italiji v preteklem stoletju, in kot organizirano dopisovanje med posamezniki, pri katerem je eden prevzel vlogo poučevalca. Dandanes je veliko možnosti za neformalen pretok znanja. Omogočata ga predvsem bliskovit razvoj medijev v zadnjih desetletjih (radio, kino, televizija, računalniki) in nova miselnost, ki je človeku odprla vrata v vseživljenjsko izobraževanje.

Začetki organiziranega iskanja znanja segajo $\mathrm{v}$ sedemdeseta leta; sama zamisel se je porodila že proti koncu šestdesetih let, ko so se v
ZDA »javno « zavedeli, da je »skrito« znanje bogastvo, ki ga je treba izrabiti. V sedemdesetih letih so se dejavno lotili področja, tako da so najprej opravili raziskavo $\mathrm{v}$ širšem smislu. Vzajemno ocenjevanje izkustvenega učenja (Cooperative Assessment of Experiential Learning), v kateri je sodelovalo 10 različnih univerz in kolidžev. Izsledki raziskave so pokazali, da je znanje, pridobljeno zunaj izobraževalnih ustanov, lahko enakovredno ali celo boljše kot znanje, pridobljeno na tradicionalnih izobraževalnih ustanovah, in da je mogoče to znanje s sodobnimi ocenjevalnimi metodami ovrednotiti. Sklenili so, da bi lahko sistem, če se bo v praksi izkazal za učinkovitega, uvrstili kot model v izobraževalne progra-

\section{Že stari grki so priznavali izkustveno učenje.} me. Pripravili so načrt za uresničevanje UPZ in omogočili vključevanje tako pridobljenih spričeval v sistem formalnega izobraževanja in morebitnega pridobivanja naslovov.

Izobraževalne ustanove $\mathrm{v} Z \mathrm{ZDA}$ so se hitro navdušile za UPZ, tako da se danes s to dejavnostjo ukvarja že več kot 1200 univerz in kolidžev. V osemdesetih letih so ameriški zgled posnemale tudi druge dežele, najprej Velika Britanija, ki je namenila precej denarja za vpeljevanje UPZ. Povabili so številne strokovnjake iz ZDA, nekaj časa pa so pošiljali tja na šolanje tudi svoje ljudi. V zadnjih letih se dejavnost širi učinkovito tudi v drugih deželah: Avstriji, na Novi Zelandiji, v Kanadi in delno Nemčiji.

Čeprav vse omenjene dežele nimajo enotnega imena za UPZ, pomeni pojem povsod približno enako: uradna potrditev poprejšnjega znanja (Accreditation of Prior Learning, Velika Britanija), priznanje poprejšnjega učenja (Recognition of Prior Learning, Avstralija), ocenjevanje poprejšnjega učenja (Prior Learning Assessment, ZDA), ocenjevanje poprejšnjega, izkustvenega učenja (Assessment of Prior Experiential Learning) ipd.

\section{UČNI DOSEŽKII}

\section{(STANDARDI ZNANJA)}

\section{Kaj so učni dosežki?}

Izraz učni dosežki smo vpeljali kot nov termin, ker za UPZ izraz »standard znanja « ni primeren. V UPZ želimo poudariti dejavni in 
uporabni vidik pridobljenega znanja, opredeliti usposobljenost, ki jo nekdo doseže z učenjem. Proces UPZ se lahko začne šele, ko so za vsa vključena področja in ravni pripravljeni učni dosežki. Ti so odločilni element procesa in prvi pogoj za njegovo izvajanje. Priprava učnih dosežkov zahteva precej razmišljanja in časa ter preskušanja v praksi. So središčna točka, iz katere izhajamo, če želimo ugotoviti, kaj zna posameznik opraviti, pripraviti, izdelati, storiti ipd. Pri raUčni dosežek je
»output« znanja. zumevanju "učnih dosežkov" pogosto nastajajo nesporazumi, ker nam glede na naše zakoreninjeno tradicionalno pojmovanje prihaja najprej na misel, da dosežki dokazujejo, kaj naj bi se posameznik $\mathrm{v}$ določeni izobraževalni ustanovi, pri delu ali pa sam naučil. V resnici učni dosežki določajo, kaj mora posameznik znati opraviti, izdelati, storiti, načrtovati ipd. Z njimi ne dokazujemo, kaj vemo, kaj znamo, ne izkazujemo "vnosa " (input) znanja, temveč »iznos « (output) znanja. $V$ tradicionalnem izobraževanju so bili učni dosežki vključeni v učni program in so določali, kaj naj bi se ljudje naučili, ocenjevanje pa je bilo osredotočeno na preverjanje znanja. Na novo zastavljeni dosežki določajo raven in vsebine znanja ter usposobljenost. Hkrati zahtevajo spremenjene metode ocenjevanja, kajti s klasičnimi metodami ne moremo oceniti posameznikovega »dejavnega « znanja. O tem bomo podrobneje spregovorili kasneje.

Tako zasnovani učni dosežki in takšna pričakovanja učnih izidov so pravzaprav bistvo korenite spremembe, ki jo prinaša UPZ.

Učne dosežke torej pripravimo vnaprej, in sicer za posamezno področje in za določeno raven. Pomembno je, da jih dobro spoznajo in razumejo vsi, ki sodelujejo v UPZ (kandidati, svetovalci, ocenjevalci, mentorji, učitelji ipd.), in da jih znajo tudi uporabljati. Prav oni ločujejo tovrstno ocenjevanje kot bistveni element UPZ od kakršnihkoli izobraževalnih programov.

\section{Kdo pripravlja in prevzema skrb za učne dosežke?}

Učne dosežke pripravlja navadno skupina strokovnjakov z določenega področja, hkrati pa je priporočljivo, da zaradi določanja upo- rabnosti znanja sodelujejo tudi delodajalci, predstavniki $\mathrm{z}$ visokošolskih ustanov ipd.

Učne dosežke je mogoče pripraviti na državni ravni, lahko pa jih samostojno pripravijo tudi različne izobraževalne ustanove, pa tudi delovne organizacije. $\mathrm{V}$ tem primeru jih mora država revidirati in potrditi.

Če poteka sprejemanje učnih dosežkov na državni ravni, je najprimernejše, da ustanovijo posebne organe, ki jih verificira vlada za posamezno področje in zastopa najrazličnejše porabnike. Ti naj bi potrdili, ali so učni dosežki smiselni in uporabni.

Ti organi lahko prevzamejo učne dosežke v »popolno oskrbo«, to pomeni, da jih najprej preverijo v poskusnem programu, uskladijo $\mathrm{z}$ ustreznimi institucijami, in če je treba, dopolnijo ali spremenijo ter prevzamejo skrb za stalno posodabljanje.

Komisijo sestavljajo strokovnjaki z določenega področja, ki pri izdelavi učnih dosežkov upoštevajo interese delodajalcev, zaposlenih, profesorjev in študentov ter širše skupnosti.

Če učni dosežki niso določeni na državni ravni, mora institucija, ki se odloči za dejavnost UPZ, organizirati njihovo pripravo po prej omenjenih načelih.

$\mathrm{V}$ industrijskem sektorju in večjih delovnih organizacijah je mogoče pripraviti učne dosežke za interno dejavnost, ki so določeni za ožjo specializacijo, vendar ima v tem primeru pridobljeno spričevalo le interno vrednost.

Čeprav učne dosežke pripravijo institucije, jih mora dokončno potrditi posebna komisija ali organ na državni ravni.

\section{UGOTAVLJANJE ZNANIA}

Ugotavljanje znanja je v UPZ faza, ki poteka od prvega srečanja kandidata $\mathrm{z}$ ustanovo UPZ do takrat, ko se začne ocenjevanje kandidatovega znanja. Medtem prevzame skrb za kandidata svetovalec/mentor, kar pomeni, da kandidat $\mathrm{z}$ njegovo pomočjo najprej ugotovi, kaj sploh želi doseči, kakšno znanje oziroma kakšne spretnosti ima in kako jih bo lahko dokazoval (izdelki, potrdila, priporočila ipd.). Na samem začetku mora kandidat razmisliti o svojih izkušnjah, pripraviti seznam znanja/spretnosti in jasno predstaviti svoja pričakovanja v zvezi z UPZ. Ugotovitve predstavi kot samooceno $\mathrm{v}$ zapisu ali na raču- 


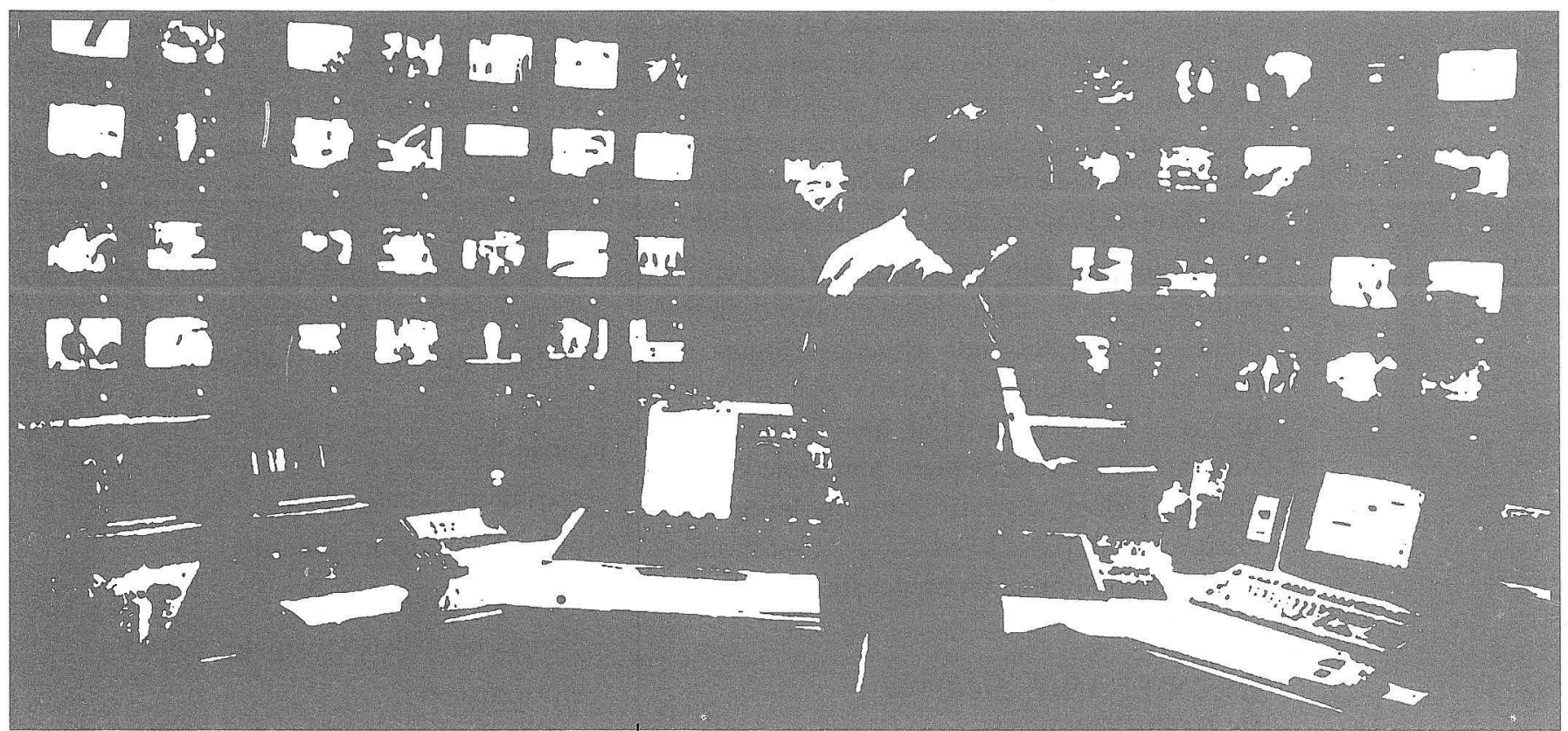

nalniškem izpisu. Takšen opis znanja lahko zajema več različnih področij, ko je pripravljen, pa je najboljše, da ga kandidat primerja z učnimi dosežki s področja, za katerega želi priznanje v sklopu UPZ. Takšen zapis imenujejo tudi "profil " kandidata. Pri pripravi zapisa o sebi potrebuje kandidat navadno svetovalčevo pomoč - daljši pogovor ali pa podroben vprašalnik, na podlagi katerega ugotavlja svoje znanje. Nekatere ustanove organizirajo pripravo zapisa $\mathrm{v}$ skupinah, saj tako sodelovanje med posamezniki ob svetovalčevem vodenju olajša delo. Pomembno je, da kandidatov zapis čim podrobneje prikaže vse potrebne informacije o njegovem znanju oziroma njegovih spretnostih, kajti čim jasneje je zapis sestavljen, toliko lažje kandidat kasneje zbere dokaze. Svetovalec mora tudi kandidata zelo natančno seznaniti s tem, kakšni dokazi so verodostojni in še veljavni.

Nato začne kandidat zbirati dokaze o svojem znanju oziroma svojih spretnostih. Vodilo pri iskanju dokazov sô splošno veljavni standardi, ki jih ima na vpogled pri ustanovi UPZ. Dokazila o znanju/spretnostih so lahko različna in niso strogo določena. Kandidat lahko sam predlaga nove vrste dokazov, če meni, da tisti, ki so na voljo v ustanovi, ne ustrezajo ali ne zadoščajo. Če so za ustanovo sprejemljivi, nadomestijo veljavna. Navadno spadajo med veljavna dokazila potrdila nekdanjih ali zdajšnih delodajalcev, ki lahko podrobno opišejo, kako se je kandidat na določenem delovnem mestu obnesel, dokazila so lahko tudi iz- delki ali prispevki z nekdanjega/ih ali zdajšnjega delovnega mesta, vendar ne smejo biti "zastarela «. O tem odloča kasneje ocenjevalec. Dokazno gradivo zbira ustanova v posebnih dosjejih, ki jih v anglosaškem svetu imenujejo "portfolios«. Zbiranje dokazov traja dlje časa, od nekaj tednov do nekaj mesecev. Ko je končano, pride na vrsto bistveni del dejavnosti, prepoznanje, ocenjevanje in potrditev znanja/spretnosti.

\section{SVETOVALEC/MENTOR}

V prvi fazi UPZ, med ugotavljanjem znanja, ima odločilno vlogo svetovalec/mentor. Ker je njegovo delo zelo specifično, pa tudi informacije in znanje, ki naj bi jih imel, potrebuje svetovalec UPZ posebno usposabljanje s pridobitvijo licence. Izkušnje kažejo, da kandidati, ki se prijavljajo za UPZ, največkrat nimajo končane formalne izobrazbe, primanjkuje jim samozavesti in niso iznajdljivi. Redkokateri potrebujejo malo ali skoraj nič pomoči. Večina potrebuje veliko vodenja in splošne pomoči, čeprav so zelo motivirani za pridobitev spričeval ali diplom. Svetovalec posreduje kandidatom podrobne informacije, jim je v oporo, jih spodbuja in včasih tudi usmerja. Kandidata vodi, vendar mu ne naroča, kaj mora storiti, njegova vloga je le, da ga spodbuja k dejavnosti in samostojnosti. Poiskati mora pravo pot in razmerje med $»$ svetovati, naročiti « in »ukazati «.

$\mathrm{Na}$ pasti pri svetovanju opozarja De Board: 
»Svetovalec, ki kandidatu naroča, kaj mora storiti, je usmerjen problemsko (osredotočen na problem). Če pa je osredotočen na problem, navadno izključi kandidata in mu s tem odvzame možnost, da le-ta prevzame večji del odgovornosti zase na svoja ramena. «(De Board, 1989)

Svetovalec tudi zelo dobro pozna možnosti za izobraževanje in usposabljanje, tako da kandidata po potrebi tudi usmerja. Dogaja se namreč, da kandidatovo znanje $\mathrm{z}$ določenega področja ali dokazila, ki jih ima, ne ustrezajo standardom. V tem primeru potrebuje kandidat za pridobitev kvalifikacije dopolnilno izobraževanje ali pa se kandidat pred vstopom $\mathrm{v}$ UPZ želi dopolnilno izobraževati.

\section{OCENJEVANJE ZNANJA IN SPRETNOSTI}

Ocenjevanje v procesu UPZ, z drugimi besedami ocenjevanje izkustvenega, poprej pridobljenega znanja, je usmerjeno v ocenjevanje uspešnosti pri opravljanju določene naloge ali pri izdelovanju predmetov. Zato ne zajema le ocenjevanja učnih dosežkov, temveč tudi

Ocenjevanje znanja in spretnosti poteka pri UPZ po dveh temeljnih postopkih:

- ocenjevanje/ovrednotenje potrdil, spričeval, priporočl, pričevanj, izdelkov, skratka vsega priloženega gradiva, zbranega $v$ dosjejih;

- preverjanje znanja $\mathrm{v}$ pogovorih $\mathrm{s}$ kandidatom, $\mathrm{v}$ opazovanju kandidata pri delu, izdelavi simuliranih nalog ipd., morebitno testiranje in včasih tudi klasični izpit.

spretnosti, sposobnosti in delovne zmogljivosti. Ocenjevanje izkustvenega učenja mora biti zelo sistematično, vsebovati mora jasno postavljene cilje, po katerih je znanje dokazljivo. Da se takšno znanje oziroma takšna spretnost lahko oceni, je treba izdelati podrobna merila, po katerih je mogoče učne dosežke oceniti. $V$ nasprotju s tradicionalnim ocenjevanjem, pri katerem je pomembno učenje, so za ocenjevanje v UPZ pomembni le slednji. Ker je pri UPZ pozornost namenjena neposrednemu ocenjevanju usposobljenosti, so tudi metode ocenjevanja drugačne, saj bolj temeljijo na opazovanju: pregled izdelkov zbiranje dokumentacije $\mathrm{v}$ daljšem časovnem obdobju, izdelanih nalog, poročil, načrtov, člankov, referatov, testiranje na delovnem mestu, simulacija delovnih nalog ipd. Ocenje- vanje poteka vedno na dveh ravneh, to pomeni, da ocenjevalčevo delo v okviru ustanove UPZ in potrdilo, ki ga ta izda, pregleda, preveri in potrdi še institucija na višji ravni.

Glede na postavljene standarde za določeno področje se potem to znanje "prevede « $v$ oblike, ki so sprejemljive za ustanove, ki podeljujejo spričevala in naslove.

Kandidat zbere v svojem dosjeju dve vrsti dokazil:

neposredna:

- računalniški programi,

- priročnik za usposabljanje,

- glasbena kompozicija,

- članek, objavljen v reviji ali časopisu,

- videoposnetki;

posredna:

- referenčna pisma prejšnjih delodajalcev ali zdajšnjega delodajalca,

- posebne nagrade/pohvale,

- članki o kandidatu (v časopisih/revijah),

- fotografije izdelkov/dela, ki ga je opravil kandidat.

Da bi zagotovili verodostojnost izdelka, kandidat priskrbi pisma treh oseb, ki potrjujejo, da je izdelek zares njegov, pripravi daljši zapis izdelovanja, pripravljen je odgovarjati na ocenjevalčeva vprašanja, ki se nanašajo na izdelavo.

Dogovoriti se je treba tudi, kakšna veljavnost izdelka je sprejemljiva, nemalokrat izdelek zastari že v enem ali dveh letih.

\section{Ocenjevalec/spraševalec}

V ocenjevalnem procesu UPZ je bolje, če ocenjuje kandidata več (2-3) ocenjevalcev, ker je tako zagotovljena večja objektivnost.

Ocenjevalec potrebuje posebno usposabljanje, še zlasti pa, če deluje v tradicionalnih izobraževalnih institucijah. Sposoben naj bi bil tudi oceniti uporabnost znanja, ne le teorijo, biti mora zanesljiv - kar pomeni, da ne niha pri svoji presoji, tako da tudi kasneje enako oceni kandidatove izdelke ali usposobljenost ipd.

\section{Postopek ocenjevanja}

Ocenjevalec se najprej seznani s kandidatovim dosjejem, da dobi splošen vtis o kandida- 
tovem znanju. Glede na dobro poznavanje učnih dosežkov na svojem področju ugotovi, do katere stopnje je kandidat že dokazal usposobljenost, in določi, kakšno dodatno preverjanje je potrebno. Nato dokaze obdela $\mathrm{z}$ več vidikov: ali ustrezajo merilom, ali so zadostni, veljavni, avtentični (zares kandidatovo delo). Če je treba, pri posrednih dokazih naveže stik z osebo, ki je napisala oceno/priporočila/članek ipd. Po končani obdelavi dokazil se odloči, kaj vse mora kandidat pripraviti za ustno srečanje, na primer pojasniti postopek izdelave izdelka, potrditi znanje, ki ga dokazila le nakazujejo, avtentičnost dokazil, aktualne sposobnosti. Znanje, ki ga v dokazilih ni mogoče prepoznati, je treba preskusiti.

\section{Metode ocenjevanja}

- Pogovor/intervju. Kandidat razloži, kako je pripravil predložen izdelek, zagovarja napisane teze, načrt dela, članke, ki jih je napisal. Iz pogovora je mogoče izluščiti znanje, ki se navezuje na izdelek, hkrati pa razbrati tudi širše splošno znanje z določenega področja.

- Projekt, naloga ali seminarsko delo. Če kandidat nima dovolj dokazil, mora pripraviti projekt, nalogo ali seminarsko delo na določenem področju. Pri taki nalogi določijo dolžino, čas izdelave, mere in druge kazalnike.

- Demonstracija (simulacija/igra vlog). Ta zahteva posebne priložnosti, ob katerih ocenjevalec opazuje kandidata pri opravljanju določene dejavnosti ali spretnosti. Ta oblika zahteva skrbno načrtovano pripravo in je uporabna za vse ravni, od preverjanja hitrega pisanja po nareku do simuliranja položajev, $v$ katerih mora kandidat rešiti določene osebne, kadrovske, finančne idr. probleme. Hkrati je zelo učinkovita za ocenjevanje celostnega znanja: analitičnega razmišljanja, sposobnosti odločanja, občutljivega odzivanja na vedenje drugih, sposobnosti sporazumevanja in načrtovanja ipd.

- Opazovanje izvajanja del na delovnem mestu (lahko tudi delo v skupini - skupinsko delo). To je zelo učinkovito, še posebno, če poteka ocenjevanje pri vsakdanjem delu. Lahko traja dlje časa, tudi na delovnem mestu je mogoče pripraviti simulacije in $\mathrm{s}$ tem časovno pospešiti ocenjevanje. Tako se poleg delovnih sposobnosti lahko ocenjuje tudi predanost delu, delovna vztrajnost in zanesljivost ter splošen odnos do dela. Pri tem lahko kandidata snemamo med opravljanjem nalog.

- Pisanje eseja. Je primerno le za določena področja, ki zahtevajo analitično razmišljanje (na različnih ravneh, sposobnost sinteze ipd.).

- Ocenjevanje spretnosti. Pri tem gre predvsem za ocenjevanje ročnih spretnosti, kot so popravilo avtomobila, elektronskih naprav ipd., vendar je pri tem razvidno tudi splošno teoretično poznavanje področja.

- Pisni izpiti in tradicionalno testiranje. V dejavnosti UPZ se, kolikor je mogoče, ogibamo tradicionalnega testiranja, vendar je včasih treba vključiti tudi to vrsto preverjanja, predvsem kot dopolnilno preverjanje, potem ko so bile "uporabljene« že druge ocenjevalne metode.

\section{LITERATURA}

Crossland, D.: Assessment of Prior Learning and Achievement, NIACE, Leister, 1991.

Simosko, S.: APL, Accreditation of Prior Learning, Kogan Page, London, 1991.

Simosko, S.: Get Qualifications For What You Know and Can Do, Kogan Page, London, 1992.

Keaton, M. T.: Experiential Learing, Jossey-Bass Publishers, London, 1976.

New Zeland Qualification Authority: The Recognition of Prior Learning, Wellington, 1993.

Jelenc, Z.: Ugotavljanje in ocenjevanje znanja v izobraževanju odraslih (Vrednotenje v izobraževanju odraslih več avtorjev), Andragoško društvo Slovenije, Ljubljana, 1987.

Jessup, G.: Outcomes/NVQs and the Emerging Model of Education and Training, The Falmer Press, London, 1991.

Fletcher, Sh.; NVQs Standards and Competence, Kogan Page, London, 1991.

Ellington, H., Percival F., Race Ph.: Handbook of Educational Technology, Kogan Page, London, 1993.

Stimson, N.: How to Write and Prepare Training Materials, Kogan Page, London, 1991.

Wood, R., Assessment and Testing, Cambridge University Press, Cambridge, 1993.

Fletcher, Sh., Competence-Based Assessment Techniques, Kogan Page, London, 1992.

Mc Kelvey, C. \& Peters, H., APL Equal Opportunities for All, Routledge, London, 1993. 